\section{Method to Determine the Root Canal Anatomic Dimension by using a New Cone-Beam Computed Tomography Software}

\author{
Mike R Bueno ${ }^{1,2}$, Cyntia R.A. Estrela ${ }^{3,4}$, José Mauro Granjeiro ${ }^{5,6}$, Manoel \\ D. Sousa-Neto ${ }^{7}$, Carlos Estrela ${ }^{8}$
}

\author{
'School of Dentistry São Leopoldo \\ Mandic, Campinas, SP, Brazil \\ ${ }^{2}$ CROIF, Cuiabá, MT, Brazil \\ ${ }^{3}$ School of Dentistry, UNIC \\ - Universidade de Cuiabá, \\ Cuiabá, MT, Brazil \\ ${ }^{4}$ School of Dentistry, Evangelical \\ University of Anápolis, Goiás, Brazil \\ ${ }^{5}$ Laboratory of Bioengineering, \\ National Institute of Metrology, \\ Quality and Technology (Inmetro), \\ Duque de Caxias, RJ, Brazil \\ ${ }^{6}$ Laboratory of Clinical Research in \\ Odontology, UFF - Universidade \\ Fluminense Federal, Niterói, Brazil \\ ${ }^{7}$ School of Dentistry of Ribeirão \\ Preto, USP - Universidade de São \\ Paulo, Ribeirão Preto, SP, Brazil \\ ${ }^{8} \mathrm{School}$ of Dentistry, UFG \\ - Universidade Federal de \\ Goiás, Goiânia, GO, Brazil
}

Correspondence: Prof. Dr. Carlos

Estrela, Setor Universitário, 74605-220,

Goiânia, GO, Brazil. Tel. +55-62-3209-

6254.e-mail: estrela3@terra.com.br

Key Words: Root canal anatomy, root canal preparation, cone beam computed tomography, e-Vol DX.

\section{Introduction}

Root canal treatment involves the removal of inflamed or infected pulp tissue, or even healthy. Particularly, the root canal preparation and filling and coronal sealing constitutes important phases which collaborate with high rates of success $(1,2)$. Among the operative procedures include the mechanical action of endodontic instruments during emptying and shaping, the microbial control carried out by irrigation substances and intracanal dressing, and sealing of the spaces present with filling materials $(3,4)$.

The planning and execution of root canal treatment requires the valuable assistance of imaging exams that identify the anatomical structures that escape the direct vision of the professional. The identification of different aspects may be observed in radiographic images, such as anatomic complexity, apical limit for root canal preparation and filling, presence of material in the root canal, dental development disturbances, and progression, regression and maintenance of apical periodontitis (AP). Conventionally, the periapical radiography have been used in the endodontic routine (4), even with its known limitations of visualization of structures in two-dimensional planes $(5,6)$.

The incorporation of cone-beam computed tomography
(CBCT) in dental practice $(7,8)$, and in special in endodontic clinical as an additional resource in the diagnosis, planning and follow-up has contributed significantly to the establishment of more efficient protocols. The accuracy of CBCT images to identify anatomic and pathologic alterations compared to panoramic and periapical radiographs has been shown to reduce the incidence of false-negative results (6).

During root canal instrumentation, the enlargement of root canal space favor the sanitization process with better access to the action of irrigating agents, intracanal medications, and root canal filling, altering the internal geometry of the root canal $(2,4)$.

A contemporary discussion has emphasized that even using flexible motor-driven instruments, untouched areas have been identified during the preparation of root canals (9-11). At the same way, studies have shown imprecision to determine the anatomical diameter by endodontic instrument at apical length $(12,13)$; however, the cervical preparation may allow establishing the anatomical diameter with smaller discrepancy values between file size and the anatomical diameter (13).

The achievement of an ideal form after completion of 
root canal preparation is challenging to the endodontist, and it requires a thorough knowledge of the internal anatomy, the characteristics of the endodontic instruments, and a psychomotor ability of professional for proper instrumentation (4).

Root canals anatomy complex prevents the appropriate access of endodontic instruments on root canal wall, which interfere on the quality of bacterial decontamination. Previous knowledge of the root canal dimension may favor a better and more precise planning for root canal preparation, considering the characteristics and dimensions of the endodontic instruments and which instrument diameter the root canal can be enlarged. Thus, this article describes and discusses a method to determine the root canal anatomic dimension by using a new cone-beam computed tomography software (e-Vol DX).

\section{Material and Methods}

The development of the e-Vol DX software (CDT Software, Bauru, SP, Brazil) enables high quality CBCT images, visualization of complex anatomical structures, precise identification of occult lesions (possibly undetected), reduction of artifacts with capability to import, work with DICOM files, and standardize image adjustments to analyze CBCT volumes from different sources (14).

An operational tool of this new software was developed to obtain measurements of anatomical structures with real dimensions, in an approximation equivalent to $0.001 \mathrm{~mm}$.

The measuring instrument was developed based on the difficulties of performing precise measurements of anatomical structures, of defining points on dental surfaces, and of adjusting the correct positions to establish the measurements. The major challenge is the demarcation of

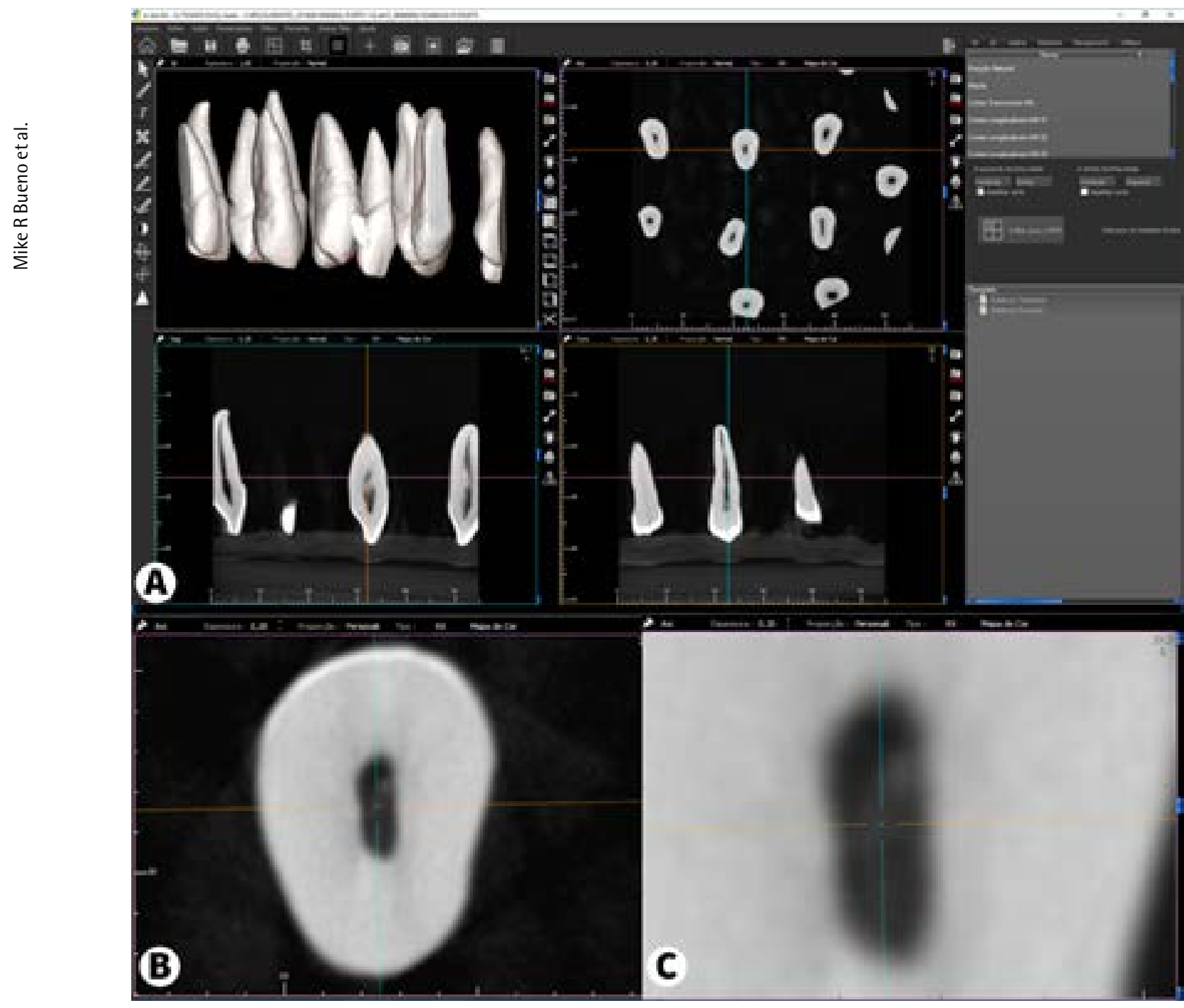

Figure 1. (A) Initial presentation of $\mathrm{CBCT}$ reports with slices in multiplanar reconstruction (MPR); (B,C) greater magnification of the image A in axial slice. 
the boundary surface to be measured, and the midpoint between the grayscale in CBCT images. It should be considered that the images are very small dimensions, which makes it difficult to repeat the measurements, besides establishing confounding variables (biases) for the correct delimitation of the reference point.

The presented method to determine the root canal anatomic dimension was developed with a new e-Vol DX software, from a CBCT image, and with the use of a specific filter made in 3 dimensional (Fig. 1).

The methodology consists in initially establishes the correct positions which will be measured, and defines the point on the edge of the anatomical structure and next adjust in intermediate position in the grayscale of CBCT image (Fig. 2). Thin sections $(0.10 \mathrm{~mm})$ are obtained from $3 \mathrm{D}$ reconstructed slices in the filter for the measurements, in order to determine initially the edge of the anatomical surface in the axial plane. The positions delimited with markings are checked in other planes in CBCT scans. A replication of positions in 3D mode is done in multiplanar reconstruction (MPR) of CBCT images (present in an access box in the e-Vol DX), where the correct position is established with the aid of a positioning guide. When it is observed that the positioning guide is not in the correct position of the margin to be measured, the adjustment is made until to obtain this position, and there is coincidence of the edge line with the center of the guide. The 3D density is adjusted so that it is in the same dimension as the $2 \mathrm{D}$ image, and a dimension calibration occurs to the point where there is a coincidence between $3 \mathrm{D}$ and 2D (2D is used as a reference). This calibration is done only at the beginning of the measurement process, once it is repeated posteriorly (Fig. 3). Next, the intermediate position of the division between the grayscale is verified in the CBCT scan. Once one side has been completed, it is moved to the other side and follows the same guidelines described. When setting the position of the courses in the other margin (another border, point to be measured), the 2D mode present in an e-Vol DX box is used as reference. Thus, one obtains the required measure, being checked in the two points (edges).

The Figure 1 characterize the initial presentation of CBCT reports with slices in multiplanar reconstruction (MPR). The Figure 2 shows the position which will be measured, and defines the point on the edge of the root canal after adjustment in intermediate position in the grayscale. The Figure 3 present the initial synchronization process of the marker in multiplanar reconstruction (MPR). The 3D density is adjusted so that it is in the same dimension as the 2D image, and a dimension calibration occurs to the point

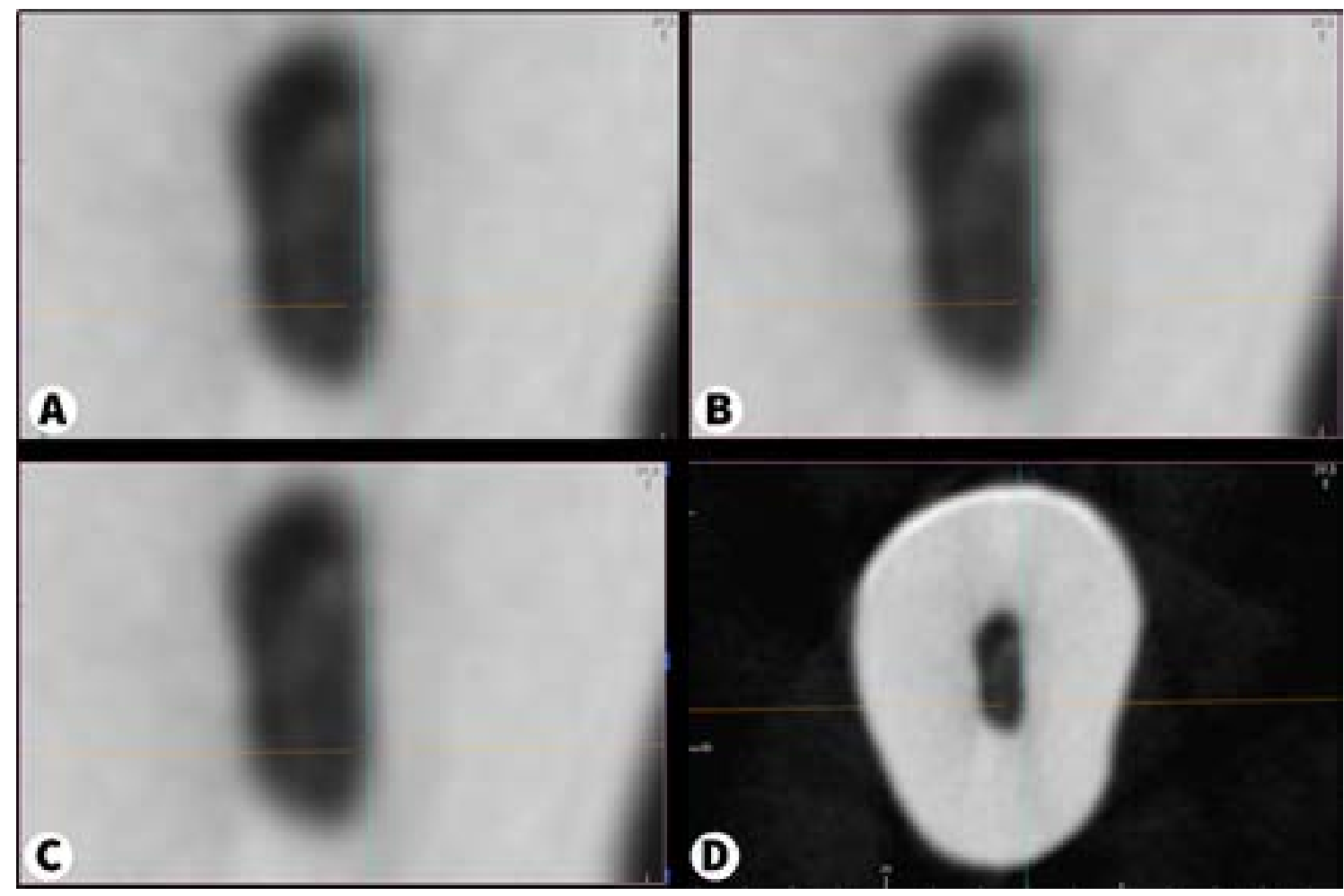

Figure 2. (A-D) CBCT report showing the position which will be measured, and defines the point on the edge of the root canal after adjustment in intermediate position in the grayscale. 
where there is a coincidence between $3 \mathrm{D}$ and $2 \mathrm{D}$ (2D is used as a reference). This calibration is done only at the beginning of the measurement process, once it is repeated. Figure 4 shows the synchronization process in MPR mode, and the conference of calibration on other edges of the root canal. Figure 5 presents the determination of the actual position of the edges of the root canal to be dimensioned with the visualization measured in micrometers. The measurements are checked on both sides of the root canal surfaces. Figure 6 show other positions of the tooth that can be measured. The 3D image dimension is not determined by the software, the reference decision was selected by the
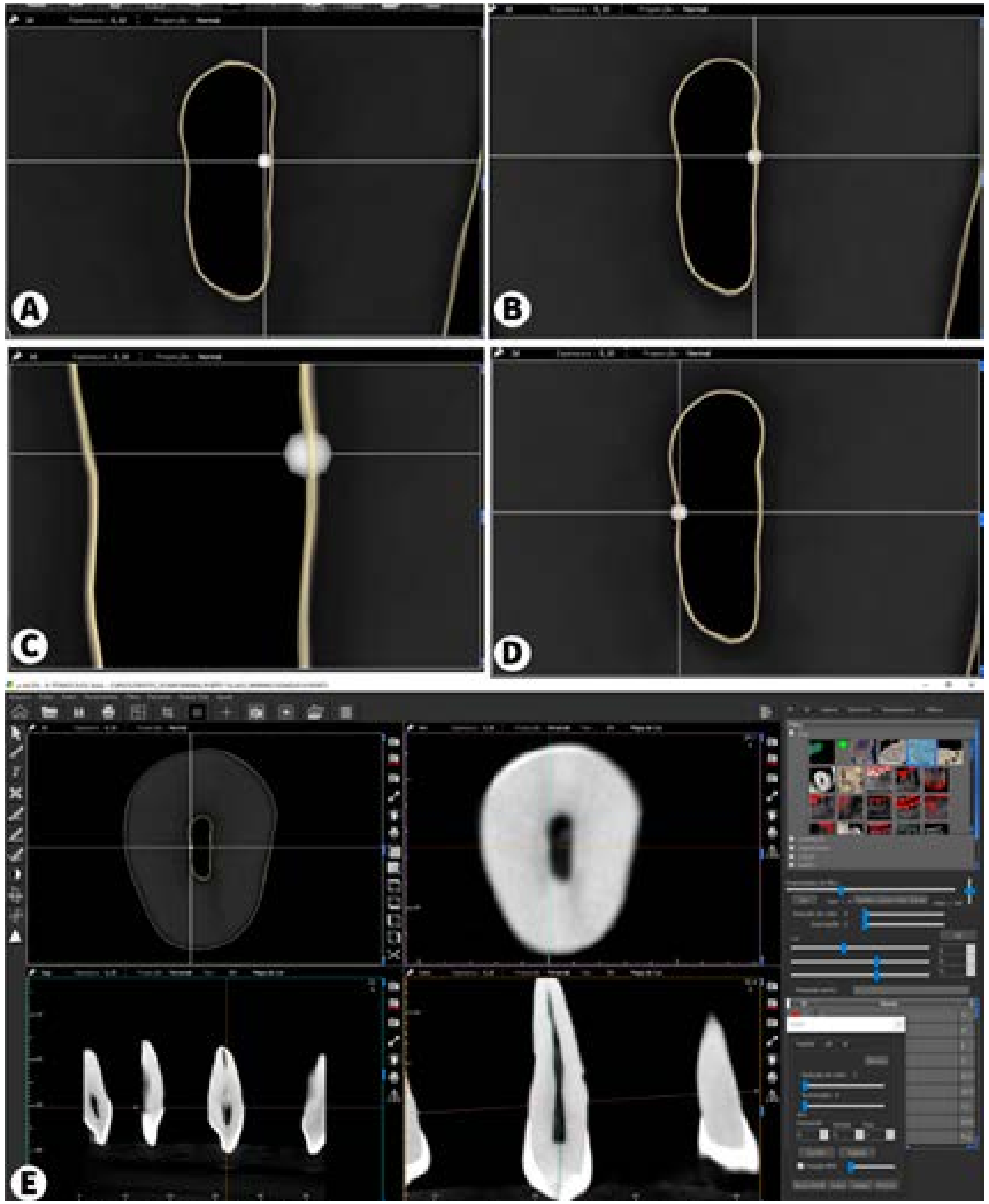

Figure 3. View of the initial synchronization process of the marker in multiplanar reconstruction (MPR). (A) 3D image without synchronization; (B-E) images with marker (guide) of synchronization; (C) greater magnification for conferring at the other edge (margin) of the root canal; The 3D density is adjusted so that it is in the same dimension as the 2D image, and a dimension calibration occurs to the point where there is a coincidence between 3D and 2D (2D is used as a reference). This calibration is done only at the beginning of the measurement process, once it is repeated. 
operator. After the operator calibrates, the software repeats in other positions.

\section{Discussion}

This method to determine the root canal anatomic dimension by using a CBCT e-Vol DX software can bring benefits in several moments of the root canal treatment, highlighting a more effective planning in determining the longitudinal and transverse limits of root canal preparation. An important impact observed in contemporary endodontics was the incorporation of CBCT on diagnoses and clinical decision-making, represented by expressive benefits as predictability in complex cases.

Bueno et al. (14) reviewed the current limitations of CBCT and presented the potential of a new CBCT software package (e-Vol DX, CDT- Brazil) with the ability to assist diagnosing, planning and managing of complex endodontic cases. The authors described that the differences between e-Vol DX and other software packages include: compatibility with all current CBCT scanners with the capacity to export DICOM Data, a more comprehensive brightness and contrast library, as other applications, in which adjustments are
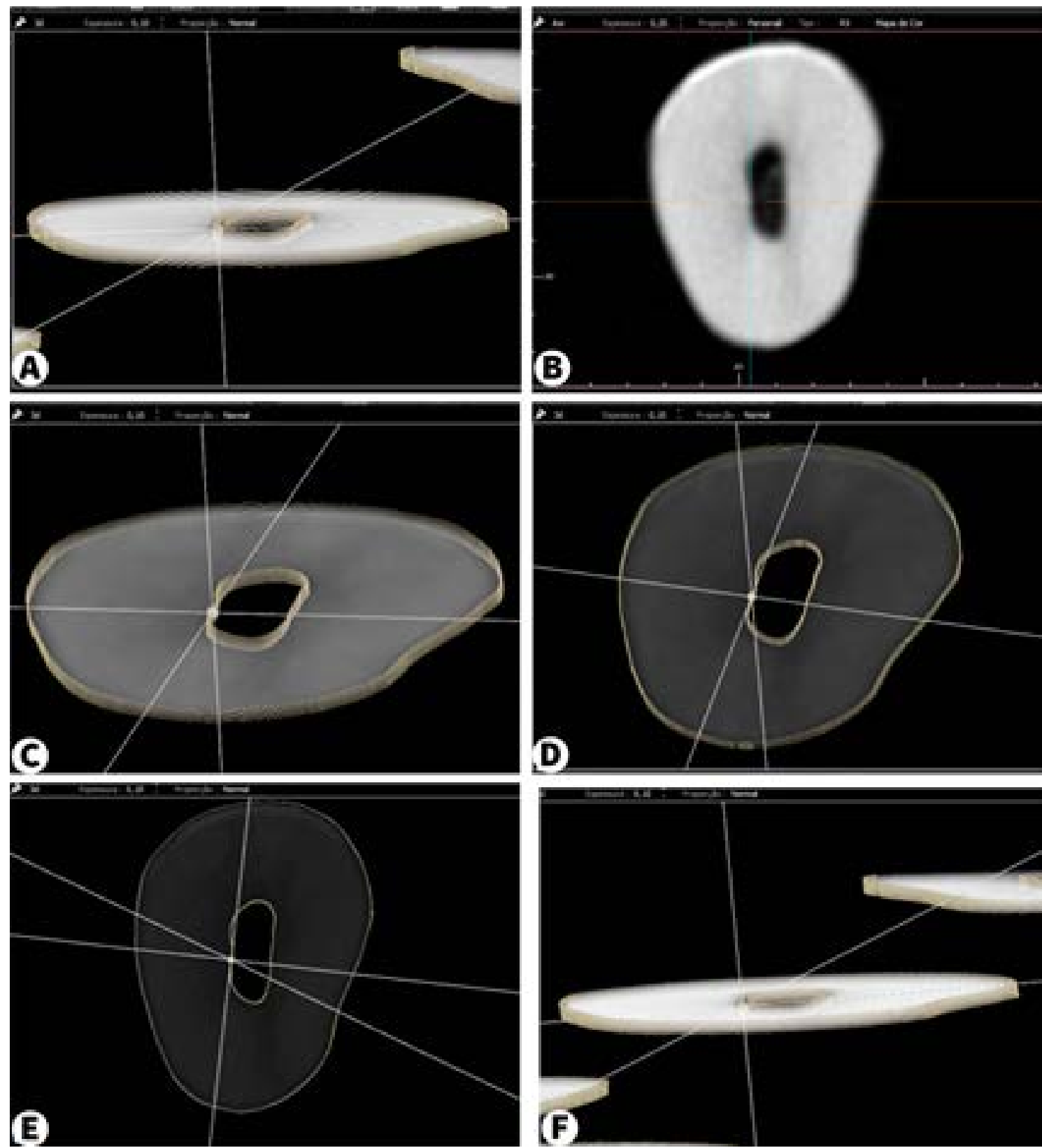

Figure 4. View of the synchronization process in MPR mode. (A) 3D image without synchronization; (B-F) 3D images with synchronization; (F) Conference of calibration on other edges of the root canal. 
limited, do not usually support all the DICOM dynamic range features; custom slice thickness adjustment, often limited and pre-defined in other applications; custom sharpening adjustment, often limited in other applications; advanced noise reduction algorithm that enhances image quality; capture screen resolution of $192 \mathrm{dpi}$, with a $384 \mathrm{dpi}$ option, in contrast to the $96 \mathrm{dpi}$ of most similar applications. Thus, this imaging method provide high resolution images due to submillimeter voxel sizes, dynamic multi-plane imaging navigation and ability to change the volume parameters such as slice thickness and slice intervals and data correction applying imaging filters and manipulating brightness and contrast. This new software also preset imaging filters, dedicated endodontic volume rendering filters with the ability to zoom the image over 1000x (3D reconstructions) without loss of resolution and automatic imaging parameters customization for better standardization and opportunities for research.

An operational tool using the e-Vol DX with endodontic filter was developed to obtain measurements of anatomical structures of small dimensions, in an approximation equivalent to $0.001 \mathrm{~mm}$. The protocol for obtaining
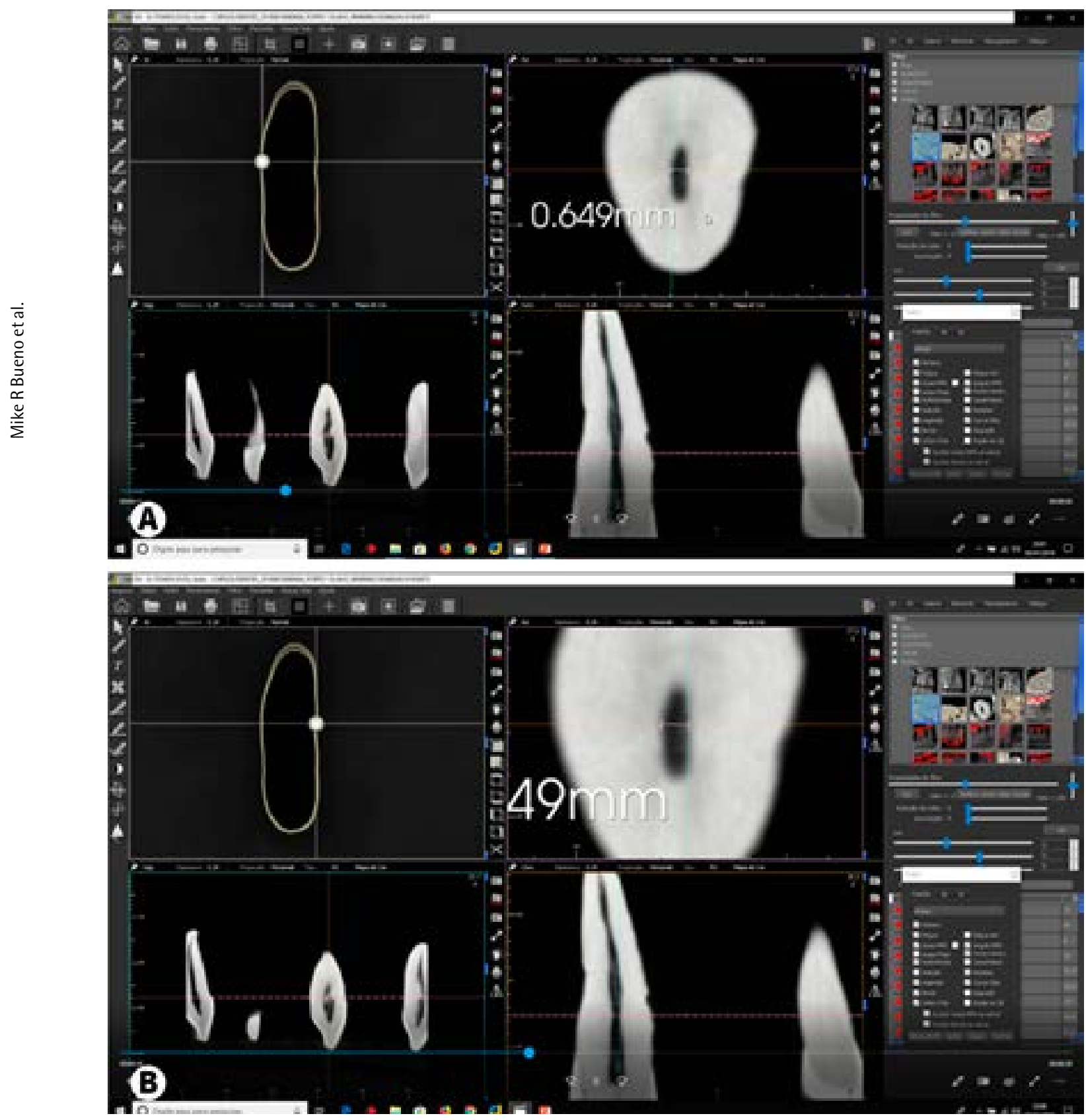

Figure 5. (A-B) CBCT report show the determination of the actual position of the edges of the root canal to be dimensioned with the visualization measured in micrometers. The measurements are checked on both sides of the root canal surfaces. 
measurements is simple, easy to apply, and avoids operator interference in the selection of points which will be measured. During the determination of an intermediate point between grayscales, errors can easily be induced because the positioning of the marker (guide) may be out of the correct position (below or beyond the midpoint). Once the measurement is repeated it hardly fits in the correct position. This method allows the calibration conference between the edges to be measured (Fig. 5). The margin delimitation of an anatomical structure to be measured in the multiplanar reconstruction (MPR) mode becomes more evident to the operator. It is important to emphasize
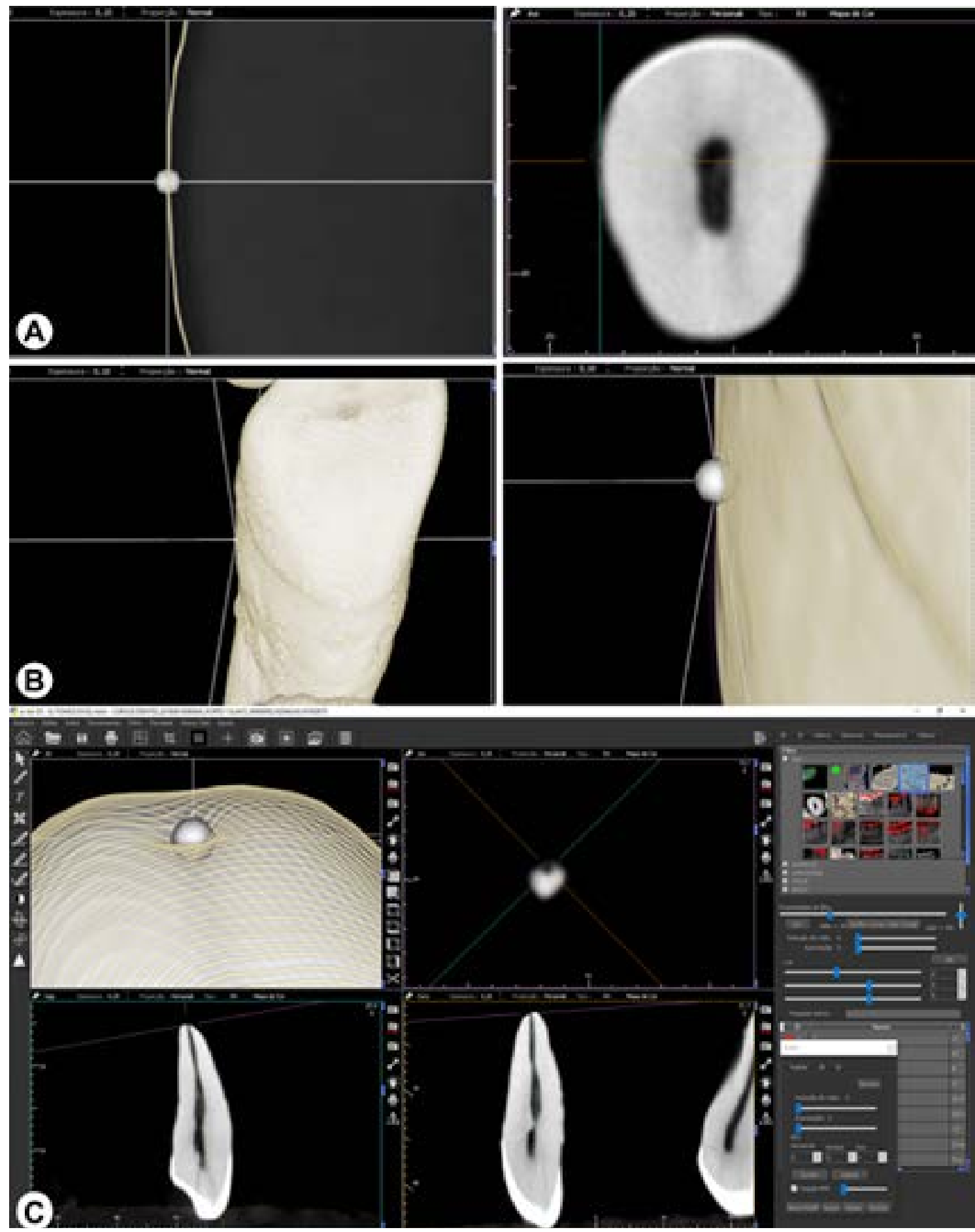

Figure 6. (A-C) Other positions of the tooth can be measured. The 3D image dimension is not determined by the software, the reference decision was selected by the operator. After the operator calibrates, the software repeats in other positions. 
that the 3D decision is not determined by the software, the reference decision is selected by the operator. Once calibrated by the operator, the software repeats in other positions (Fig. 6). Another important aspect to be mentioned relates to the coincidence in size calibration between $3 \mathrm{D}$ and $2 \mathrm{D}$, since $2 \mathrm{D}$ represents a reference.

The specific software developed by the various manufacturers of CBCT devices provides tools for measurements that have been used in several previous studies (15-19). These devices were useful to determine distances of anatomical structures; in the planning of guides for parendodontic surgery; guided access cavity preparation; in root length and bone level measurements, the relationship between teeth and anatomical structures, periapical lesions and root resorption, among several other alternatives which can be applied in several areas of dentistry (15-22).

Another peculiarity of the benefits that emerged after the application of CBCT in endodontics was the characterization of different methodologies of studies and researches (17-23). Thus, the 3D navigation strategies in CBCT images allowed better exploration and definition of new parameters for endodontic research $(23,24)$.

Among the methods of study that were developed from the use of CBCT tecnology applied to clinical resolution of endodontic problems can be found: the determination of human permanent dental development stages based on linear measurements (17); the evaluation of periapical lesions and their association with maxillary sinus abnormalities; the study of anatomical relationship between posterior teeth and maxillary sinus floor (18); the method for determination of root curvature radius (20); a new periapical index based on CBCT (21); the method to evaluate inflammatory root resorption (22); the mapreading strategy to diagnose root perforations near metallic intracanal posts (23); the frequency of root canal isthmi in human permanent teeth (24); the apical foramen position in relation to proximal root surfaces of human permanent teeth determined by using a new CBCT software (25).

In summary, the creation of this filter in the e-Vol DX software for measurement, and its appropriate managment allows more effective applications when it is desired to obtain diameters of anatomical structures. Further studies should be developed to validate the methodology presented and verify the potential clinical application of this new CBCT e-Vol DX software.

\section{Resumo}

Este estudo discute um método para determinar a dimensão anatômica do canal radicular usando o software e-Vol DX. A metodologia consiste em estabelecer as posições corretas que serão medidas, definir o ponto na borda da estrutura anatômica e ajustar a posição intermediária na escala de cinza na imagem em tomografia computadorizada de feixe cônico
(TCFC). A seguir, slices finos $(0,10 \mathrm{~mm})$ são obtidos a partir de cortes 3D reconstruídos no filtro para as medidas, a fim de determinar inicialmente a borda da superfície anatômica no plano axial. Uma replicação de posições no modo 3D é feita em reconstrução multiplanar (MPR) em imagens de TCFC, onde a posição correta é estabelecida com o auxilio de um guia de posicionamento. A densidade 3D é ajustada de modo a ficar na mesma dimensão da imagem $2 \mathrm{D}$, e então realiza-se uma calibração de dimensão até o ponto em que há uma coincidência entre o modo 3D e 2D. Essa calibração é feita apenas no início da medição. Posteriormente, a posição intermediária da divisão entre a escala de cinza é verificada na TCFC. Uma vez que um lado tenha sido concluído, o guia é movido para o outro lado, e segue-se as mesmas diretrizes descritas. Define-se a posição do marcador na outra margem, sendo que o modo 2D usado como referência. Assim, obtém-se a medida necessária, sendo verificado nas duas margens do canal radicular. A criação deste filtro no software e-Vol DX para medição e seu uso apropriado permite aplicações eficazes quando se deseja obter diâmetros de estruturas anatômicas.

\section{Acknowledgements}

Supported in part by grants from the National Council for Scientific and Technological Development (CNPq grants 306682/2017-6 to C.E.).

\section{References}

1. Holland R, Otoboni-Filho JA, Souza V, Mello W, Nery MJ, Bernabé PFE, Dezan-Jr E. Calcium hydroxide and corticosteroid-antibiotic association as dressings in cases of biopulpectomy. A comparative study in dogs teeth. Braz Dent J 1998; 9:67-76.

2. Holland R, Gomes-Filho JE, Cintra LT, Queiroz IOA, Estrela C. Factors affecting the periapical healing process of endodontically treated teeth. J Appl Oral Sci 2017;25:465-476.

3. Peters $0 A$. Current challenges and concepts in the preparation of root canal systems: A review. J Endod 2004;30:559-567.

4. Estrela $C$, Holland $R$, Estrela CR, Alencar AH, Sousa-Neto MD, Pécora JD. Characterization of successful root canal treatment. Braz Dent J 2014;25:3-11.

5. Bender IB. Factors influencing the radiographic appearance of bony lesions. J Endod 1982,8:161-170.

6. Estrela C, Bueno MR, Leles CR, Azevedo B, Azevedo JR. Accuracy of cone beam computed tomography and panoramic and periapical radiography for detection of apical periodontitis. J Endod 2008;34:273-279.

7. Arai $Y$, Tammisalo E, Iwai K, Hashimoto $K$, Shinoda K. Development of a compact computed tomographic apparatus for dental use. DentMaxillofac Radiol 1999;28:245-248.

8. Mozzo P, Procacci C, Taccoci A, Martini PT, Andreis IA. A new volumetric CT machine for dental imaging based on the cone-beam technique: preliminary results. Eur Radiol 1998;8:1558-1564.

9. Peters OA, Laib A, Göhring TN, Barbakow F. Changes in root canal geometry after preparation assessed by high-resolution computed tomography. J Endod 2001;27:1-6.

10. Siqueira-Jr JF, Rôças IN, Marceliano-Alves MF, Pérez AR; Ricucci D. Unprepared root canal surface areas: causes, clinical implications, and therapeutic strategies. Braz Oral Res 2018;32(suppl):e65:2-19.

11. Sousa-Neto MD, Silva-Sousa YC, Mazzi-Chaves JF, Carvalho KK, Barbosa AFS, Versiani MA, et al. Root canal preparation using microcomputed tomography analysis: a literature review. Braz Oral Res 2018;32(suppl):e66:20-43.

12. Wu MK, Barkis D, Roris A, Wesselink PR. Does the first file to bind correspond to the diameter of the canal in the apical region? Int Endod J 2002;35:264-267.

13. Pécora JD, Capelli A, Guerisoli DM, Spanó JC, Estrela C. Influence of cervical preflaring on apical file size determination. Int Endod $J$ 2005:38:430-435.

14. Bueno MR, Estrela C, Azevedo BC, Diogenes A. Development of a new cone-beam computed tomography software for endodontic diagnosis. Braz Dent J 2018;29:517-529.

15. Pinsky HM, Dyda S, Pinsky RW, Misch KA, Sarment DP. Accuracy of three- 
dimensional measurements using cone-beam CT. Dentomaxillofacial Radiol 2006;35:410-416.

16. Ludlow JB, Laster WS, See M. Accuracy of measurements of mandibular anatomy in cone beam computed tomography images. Oral Surg Oral Med Oral Pathol Oral Radiol Endod 2007;103:534-542.

17. Estrela C, Valladares-Neto J, Bueno MR, Guedes OA, Porto OCL, Pécora JD. Linear measurements of human permanent dental development stages using Cone-Beam Computed Tomography: a preliminary study. Dental Press J Orthod 2010;15:44-78.

18. Nunes $\mathrm{CABCM}$, Guedes $\mathrm{OA}$, Alencar AHG, Peters OA, Estrela CRA, Estrela C. Evaluation of periapical lesions and their association with maxillary sinus abnormalities on cone-beam computed tomographic images. J Endod 2015;42:42-46.

19. Buchgreitz J, Buchgreitz M, Mortensen D, Bjørndal L. Guided access cavity preparation using cone-beam computed tomography and optical surface scans-an ex vivo study. Int Endod J 2016;49:790-795.

20. Estrela C, Bueno MR, Sousa-Neto MD, Pécora JD. Method for determination of root curvature radius using cone-beam computed tomography images. Braz Dent J 2008;19:114-118.
21. Estrela C, Bueno MR, Azevedo B, Azevedo JR, Pécora JD. A new periapical index based on cone beam computed tomography. J Endod 2008;34:1325-1331.

22. Estrela $\mathrm{C}$, Bueno MR, Alencar AHG Mattar R, Valladares-Neto J, Azevedo $B C$, Estrela CRA. Method to evaluate inflammatory root resorption by using cone beam computed tomography. J Endod 2009; 35:1491-1497.

23. Bueno MR, Estrela C, Figueiredo JAP, Azevedo BC. Map-reading strategy to diagnose root perforations near metallic intracanal posts by using cone beam computed tomography. J Endod 2011;37:85-90.

24. Estrela C, Rabelo LE, Souza JB, Alencar AHG, EstrelaCRA, SousaNeto MD. Frequency of root canal isthmi in human permanent teeth determined by cone-beam computed tomography. J Endod 2015;41:1535-1539.

25. Estrela C, Couto GS, Bueno MR, Bueno KG, Estrela LRA, Porto OCL, et al. Apical foramen position in relation to proximal root surfaces of human permanent teeth determined by using a new cone-beam computed tomographic software. J Endod 2018;44:1741-1748.

Received September 12, 2018 Accepted November 5, 2018 